Jurnal Cendekia Akuntansi

Kediri, Desember 2020

\title{
ANALISIS STRUKTUR MODAL YANG OPTIMAL PADA PERUSAHAAN ROKOK YANG TERDAFTAR DI BURSA EFEK INDONESIA PERIODE 2016-2018
}

\author{
Linda Riani \\ Nindi Vaulia Puspita \\ Kartika Yuliari \\ Fakultas Ekonomi - Universitas Kadiri \\ E-mail: nindi.vaulia@unik-kediri.ac.id
}

\begin{abstract}
Abstrak
Penelitian ini bertujuan untuk mengetahui struktur modal yang optimal pada perusahaan rokok yang terdaftar di Bursa Efek Indonesia periode 2016-2018. Sampel dalam penelitian ini adalah semua perusahaan rokok yang terdaftar di Bursa Efek Indonesia periode 2016-2018. Metode analisis data dilakukan dengan cara menghitung rasio keuangan perusahaan yang terdiri dari total debt to total assets ratio, total debt to equity ratio dan long term debt to equity ratio, menghitung komposisi struktur modal tiap tahun perusahaan, menghitung biaya modal perusahaan dan menganalisis optimalisasi struktur modal dengan cara membandingkan struktur modal perusahaan dengan biaya modal (WACC). Hasil penelitian menunjukkan bahwa struktur modal yang optimal pada perusahaan rokok yang terdaftar di Bursa Efek Indonesia tperiode 2016-2018 terjadi pada tahun 2018, yaitu pada saat biaya modal rata-rata tertimbang perusahaan minimum dengan proporsi DAR sebesar 30,6\%, DER sebesar 46,9\% dan LDER sebesar 6,7\%.
\end{abstract}

Kata kunci: Bursa Efek Indonesia; DAR;DER;LDER;WACC.

\begin{abstract}
Abstrack
This study aims to determine the optimal capital structure of cigarette companies listed on the Indonesia Stock Exchange for the period 2016-2018. The sample in this study is all cigarette companies listed on the Indonesia Stock Exchange for the period 2016-2018. The data analysis method is done by calculating the company's financial ratios consisting of total debt to total assets ratio, total debt to equity ratio, total debt to equity ratio and long term debt to equity ratio. Calculating the composition of the company's capital structure each year, calculating the company's cost of capital and analyzing the optimization of the capital structure by comparing the company's capital structure with the cost of capital (WACC). The results show that the optimal capital structure in cigarette companies listed on the Indonesia Stok Exchange in the 2016-2018 period occured in 2018, when the company weigh average cost of capital was minimum with a DAR proportion of $30,6 \%$, DER of 46,9\% and LDER at 6,7\%.
\end{abstract}

Keywords: Indonesia Stock Exchange; DAR; DER; LDER; WACC. 


\section{PENDAHULUAN}

Perusahaan lokal ataupun perusahaan internasional bersaing semakin ketat dan dituntut untuk mampu menghadapi pasar yang kompetitif pada era globalisasi saat ini. Dengan adanya persaingan antar perusahaan maka akan memberikan sebuah tantangan kepada perusahaaan tersebut agar mampu untuk berkembang dan menjadi perusahaan besar. Para pemimpin perusahaan dituntut untuk bisa menjalankan dan mengelola semua kegiatan perusahaan dengan cara yang benar sehingga dapat mengoptimalkan kinerja perusahaan. Perusahaan harus meningkatkan jumlah modal agar mampu bertahan menghadapi persaingan yang semakin ketat untuk mengoptimalkan kinerja perusahaan.

Struktur modal merupakan hal yang tidak boleh dianggap remeh oleh perusahaan karena baik buruknya struktur modal akan berdampak secara langsung kepada kondisi keuangan perusahaan yang pastinya akan mempengaruhi nilai perusahaan tersebut.Perusahaan harus mampu menentukan sumber modal yang memiliki biaya rendah dalam menggunakan sumber-sumber modal (Riyanto, 2010:294). Tujuan jangka panjang yang harus dimiliki perusahaan adalah memaksimalkan nilai perusahaan yang berarti akan memaksimalkan kemakmuran para pemegang sahamnya (Arif, 2018).

Berdasarkan penelitian terdahulu tentang struktur modal yang optimal ditemukan beberapa hasil penelitian yang berbeda. Menurut hasil penelitiannya (Siliwadi \& Muliawani, 2018) mengungkapkan bahwa struktur modal yang optimal terjadi ketika biaya modal rata-rata tertimbang perusahaan minimun. (Rustam, 2015) dalam hasil penelitiannya mengungkapkan bahwa struktur modal yang optimal terjadi ketika keseimbangan antara jumlah penggunaan hutang jangka panjang dan ekuitas dengan porsi jumlah hutang jangka panjang hampir sama dengan jumlah ekuitas. Sedangkan menurut hasil penelitian (Sulistio \& Saifi, 2017) mengungkapkan bahwa struktur modal yang optimal terjadi ketika hutang jangka panjang lebih kecil dari modal sendiri.

Bursa Efek Indonesia mencatat salah satu sektor industri barang konsumsi adalah industri rokok. Industri rokok merupakan salah satu jenis usaha yang mengalami kemajuan pesat dan menjadi penyumbang pendapatan negara yang lumayan besar di Indonesia. Agar tetap unggul dan mampu menghadapi pertumbuhan dan persaingan yang semakin ketat, perusahaan harus mampu meningkatkan kinerja perusahaan. Dengan mengetahui struktur modal yang optimal, perusahaan rokok dapat melakukan pengelolaan sumber dana dengan biaya yang minimal dan tentunya juga menguntungkan perusahaan. Berdasarkan latar belakang diatas peneliti tertarik untuk mengambil penelitian berjudul "Analisis Struktur Modal yang Optimal Pada Perusahaan Rokok yang Terdaftar Di Bursa Efek Indonesia Periode 2016-2018”.

\section{Rumusan Masalah}

Berdasarkan latar belakang yang telah diuraikan di atas, maka rumusan masalah dalam penelitian ini adalah "Bagaimanakah struktur modal yang optimal pada perusahaan rokok yang terdaftar di BEI periode 2016-2018?”. 


\section{Tujuan Penelitian}

Berdasarkan masalah yang dipaparkan, tujuan penelitian ini adalah untuk mengetahui struktur modal yang optimal pada perusahaan rokok yang terdaftar di BEI periode 2016-2018.

\section{TINJAUAN PUSTAKA}

Struktur modal merupakan bauran sumber pendanaan permanen (jangka panjang) yang digunakan perusahaan untuk memberikan hasil analisis yang lengkap tentang bagaimana cara perusahaan memanfaatkan aktiva dan sekaligus membelanjakan aktiva tersebut.

\section{Rasio Struktur Modal}

Menurut (Sjahrial dan Purba,2013) rasio struktur modal terdiri dari:

1. Total Debt to Total Assets Ratio (DAR). Rasio ini digunakan untuk mengukur seberapa besar jumlah aktiva perusahaan yang dibiayai dengan hutang.

2. Total Debt to Equity Ratio(DER). Rasio ini digunakan untuk mengukur perimbangan antara kewajiban yang dimiliki perusahaan dengan modal sendiri.

3. Long Term Debt to Equity Ratio(LDER). Rasio ini digunakan untuk menunjukkan hubungan antara jumlah pinjaman jangka panjang yang diberikan kreditur dengan jumlah modal sendiri yang diberikan oleh pemilik perusahaan.

\section{Biaya Modal Rata-Rata Tertimbang (WACC)}

(Kamaludin dan Indriani, 2012) mengatakan bahwa setiap perusahaan menginginkan mempunyai struktur modal yang optimal. Struktur modal dapat dioptimalkan biasanya dengan menggunakan keragaman atau campuran hutang, saham preferen dan ekuitas.

\section{METODE PENELITIAN}

\section{Populasi dan Sampel}

Sampel dalam penelitian ini adalah perusahaan rokok yang terdaftar di Bursa Efek Indonesia periode 2016-2018. Perusahaan yang menjadi sampel dalam penelitian ini adalahPT Gudang Garam Tbk (GGRM), PT Hanjaya Mandala Sampoerna Tbk (HMSP), Bentoel International Investama Tbk (RMBA) dan Wismilak Inti Makmur Tbk (WIIM).

\section{Metode Analisis Data}

Dalam penelitian ini, teknik analisis data yang dilakukan antara lain sebagai berikut:

1. Menghitung rasio keuangan perusahaan yang terdiri dari:

2. Menghitung komposisi struktur modal tiap tahun pada periode $2016-2018$

3. Menghitung biaya modal perusahaan tiap tahun pada periode 2016-2018

4. Menganalisis optimalisasi struktur modal dengan cara membandingkan struktur modal perusahaan dengan biaya modal (WACC) terkecil dari tahun ke tahun. Struktur modal suatu perusahaan dikatakan optimal apabila nilai WACC (biaya modal) $\leq$ DAR, DER, LDER. 


\section{HASIL PENELITIAN DAN PEMBAHASAN}

Tabel 1 Struktur Modal Perusahaan Rokok

\begin{tabular}{|l|l|l|l|l|l|}
\hline Kode Saham & Tahun & DAR & DER & LDER & Rata-rata \\
\hline GGRM & 2016 & $37,2 \%$ & $59,1 \%$ & $4,4 \%$ & $33,6 \%$ \\
& 2017 & $36,8 \%$ & $58,2 \%$ & $4,6 \%$ & $33,2 \%$ \\
& 2018 & $34,7 \%$ & $53 \%$ & $4,3 \%$ & $30,7 \%$ \\
\hline \multirow{2}{*}{ HMSP } & 2016 & $19,6 \%$ & $24,4 \%$ & $5,6 \%$ & $16,5 \%$ \\
& 2017 & $20,9 \%$ & $26,5 \%$ & $7,5 \%$ & $18,3 \%$ \\
& 2018 & $24,1 \%$ & $31,8 \%$ & $6,9 \%$ & $20,9 \%$ \\
\hline RMBA & 2016 & $29,9 \%$ & $42,7 \%$ & $4,3 \%$ & $25,6 \%$ \\
& 2017 & $36,6 \%$ & $57,8 \%$ & $5,3 \%$ & $33,2 \%$ \\
& 2018 & $43,8 \%$ & $77,8 \%$ & $5,8 \%$ & $42,5 \%$ \\
\hline \multirow{2}{*}{ WIIM } & 2016 & $26,8 \%$ & $36,6 \%$ & $6,9 \%$ & $23,4 \%$ \\
& 2017 & $20,2 \%$ & $25,3 \%$ & $8,9 \%$ & $18,1 \%$ \\
& 2018 & $19,9 \%$ & $24,9 \%$ & $9,9 \%$ & $18,2 \%$ \\
\hline \multicolumn{2}{|l|}{ Rata-rata perusahaan } & $\mathbf{2 9 , 2 \%}$ & $\mathbf{4 3 , 2}$ & $\mathbf{6 , 2 \%}$ & $\mathbf{3 1 4 , 2 \%}$ \\
\hline
\end{tabular}

\section{Sumber: Data diolah}

Berdasarkan tabel di atas dapat diketahui bahwa struktur modal perusahaan rokok yang terdaftar di Bursa Efek Indonesia pada periode 2016-2018, dilihat dari rata-rata total debt to total assets ratio (DAR) sebesar $29,2 \%$, rata-rata total debt to equity ratio (DER) sebesar $43,2 \%$ dan rata-rata long term debt to equity ratio(LDER) sebesar 6,2\%. Perusahaan yang memiliki rata-rata struktur modal yang tertinggi adalah perusahaan Bentoel International Investama Tbk (RMBA) pada tahun 2018 sebesar 42,5\% dengan komposisi total debt to total assets ratio (DAR) sebesar 43,8\%, total debt to equity ratio (DER) sebesar 77,8\% dan long term debt to equity ratio(LDER) sebesar 5,8\%.

Kombinasi dari modal sendiri dan hutang yang digunakan oleh perusahaan disebut dengan struktur modal. Berdasarkan hasil analisis perhitungan struktur modal yang diukur dengan menggunakan rasio DAR, DER dan LDER pada perusahaan rokok yang terdaftar di Bursa Efek Indonesia periode 2016-2018 maka dapat dijelaskan bahwa:

\section{PT Gudang Garam Tbk (GGRM)}

Tabel 2 Struktur Modal GGRM

\begin{tabular}{|c|c|c|c|c|}
\hline Tahun & DAR & DER & LDER & Rata-rata \\
\hline 2016 & $37,2 \%$ & $59,1 \%$ & $4,4 \%$ & $33,6 \%$ \\
\hline 2017 & $36,8 \%$ & $58,2 \%$ & $4,6 \%$ & $33,2 \%$ \\
\hline 2018 & $34,7 \%$ & $53 \%$ & $4,3 \%$ & $30,7 \%$ \\
\hline
\end{tabular}

\section{Sumber: Data diolah}

Berdasarkan tabel di atas dapat diketahui bahwa rata-rata struktur modal tertinggi terjadi pada tahun 2016 sebesar 33,6\% dengan kombinasi total debt to total assets ratio (DAR) sebesar 37,2\%, total debt to equity ratio (DER) sebesar $59,1 \%$ dan long term debt to equity ratio (LDER) sebesar $4,4 \%$. 
2. PT Hanjaya Mandala Sampoerna Tbk (HMSP)

Tabel 3 Struktur Modal HMSP

\begin{tabular}{|c|c|c|c|c|}
\hline Tahun & DAR & DER & LDER & Rata-rata \\
\hline 2016 & $19,6 \%$ & $24,4 \%$ & $5,6 \%$ & $16,5 \%$ \\
\hline 2017 & $20,9 \%$ & $26,5 \%$ & $7,5 \%$ & $18,3 \%$ \\
\hline 2018 & $24,1 \%$ & $31,8 \%$ & $6,9 \%$ & $20,9 \%$ \\
\hline
\end{tabular}

\section{Sumber: Data diolah}

Berdasarkan tabel di atas dapat diketahui bahwa rata-rata struktur modal tertinggi terjadi pada tahun 2018 sebesar 20,9\% dengan kombinasi total debt to total assets ratio (DAR) sebesar $24,1 \%$, total debt to equity ratio (DER) sebesar $31,8 \%$ dan long term debt to equity ratio (LDER) sebesar 6,9\%.

\section{Bentoel International Investama Tbk (RMBA)}

Tabel 4 Struktur Modal RMBA

\begin{tabular}{|c|c|c|c|c|}
\hline Tahun & DAR & DER & LDER & Rata-rata \\
\hline 2016 & $29,9 \%$ & $42,7 \%$ & $4,3 \%$ & $25,6 \%$ \\
\hline 2017 & $36,6 \%$ & $57,8 \%$ & $5,3 \%$ & $33,2 \%$ \\
\hline 2018 & $43,8 \%$ & $77,8 \%$ & $5,8 \%$ & $42,5 \%$ \\
\hline
\end{tabular}

\section{Sumber: Data diolah}

Berdasarkan tabel di atas dapat diketahui bahwa rata-rata struktur modal tertinggi terjadi pada tahun 2018 sebesar 42,5\% dengan kombinasi total debt to total assets ratio (DAR) sebesar $43,8 \%$, total debt to equity ratio (DER) sebesar $77,8 \%$ dan long term debt to equity ratio (LDER) sebesar 5,8\%.

\section{Wismilak Inti Makmur Tbk (WIIM)}

Tabel 5 Struktur Modal WIIM

\begin{tabular}{|c|c|c|c|c|}
\hline Tahun & DAR & DER & LDER & Rata-rata \\
\hline 2016 & $26,8 \%$ & $36,6 \%$ & $6,9 \%$ & $23,4 \%$ \\
\hline 2017 & $20,2 \%$ & $25,3 \%$ & $8,9 \%$ & $18,1 \%$ \\
\hline 2018 & $19,9 \%$ & $24,9 \%$ & $9,9 \%$ & $18,2 \%$ \\
\hline
\end{tabular}

\section{Sumber: Data diolah}

Berdasarkan tabel di atas dapat diketahui bahwa rata-rata struktur modal tertinggi terjadi pada tahun 2016 sebesar 23,4\% dengan kombinasi total debt to total assets ratio (DAR) sebesar 26,8\%, total debt to equity ratio (DER) sebesar $36,6 \%$ dan long term debt to equity ratio (LDER) sebesar 6,9\%.

Analisis Biaya Modal Rata-rata Tertimbang (WACC)

Tabel 6 Hasil Analisis WACC Perusahaan Rokok

\begin{tabular}{|c|c|c|c|c|c|c|c|}
\hline Kode Saham & Tahun & D & Rd & T & E & Re & WACC \\
\hline \multirow{3}{*}{ GGRM } & 2016 & 0,4 & 0,7 & 0,2 & 0,6 & 0,2 & 0,34 \\
& 2017 & 0,4 & 0,4 & 0,2 & 0,7 & 0,2 & 0,27 \\
& 2018 & 0,3 & 0,3 & 0,2 & 0,7 & 0,2 & 0,21 \\
\hline \multirow{3}{*}{ HMSP } & 2016 & 0,2 & 0,06 & 0,2 & 0,8 & 0,4 & 0,33 \\
& 2017 & 0,2 & 0,03 & 0,2 & 0,8 & 0,4 & 0,32 \\
& 2018 & 0,2 & 0,04 & 0,2 & 0,8 & 0,4 & 0,33 \\
\hline
\end{tabular}




\begin{tabular}{|c|c|c|c|c|c|c|c|}
\hline \multirow{3}{*}{ RMBA } & 2016 & 0,3 & 0,03 & 0,2 & 0,7 & 0,2 & 0,15 \\
& 2017 & 0,4 & 0,5 & 0,1 & 0,6 & 0,05 & 0,21 \\
& 2018 & 0,4 & 0,04 & 0,3 & 0,6 & 0,07 & 0,05 \\
\hline \multirow{3}{*}{ WIIM } & 2016 & 0,3 & 0,2 & 0,2 & 0,7 & 0,1 & 0,12 \\
& 2017 & 0,2 & 0,07 & 0,2 & 0,8 & 0,04 & 0,04 \\
& 2018 & 0,2 & 0,01 & 0,3 & 0,8 & 0,05 & 0,04 \\
\hline
\end{tabular}

\section{Sumber: Data diolah}

Berdasarkan hasil perhitungan dalam tabel di atas dapat disimpulkan bahwa WACC perusahaan rokok yang terdaftar di Bursa Efek Indonesia selama periode 2016-2018 setiap tahunnya berfluktuasi. Untuk menilai struktur modal yang optimal pada perusahaan rokok yang terdaftar di Bursa Efek Indonesia selama periode 2016-2018, maka struktur modal yang diukur dengan menggunakan DAR, DER dan LDER dapat dibandingkan dengan struktur modal yang diukur dengan WACC.

\section{Perbandingan nilai DAR, DER, LDER dan WACC}

Tabel 7 Perbandingan nilai DAR, DER, LDER dan WACC

\begin{tabular}{|c|c|c|c|c|}
\hline Tahun & DAR & DER & LDER & WACC \\
\hline 2016 & 28,4 & 40,7 & 5,3 & 0,24 \\
\hline 2017 & 28,6 & 41,9 & 6,6 & 0,21 \\
\hline 2018 & 30,6 & 46,9 & 6,7 & 0,16 \\
\hline
\end{tabular}

\section{Sumber: Data diolah}

Berdasarkan tabel di atas dapat dilihat bahwa nilai WACC perusahaan tertinggi terjadi pada tahun 2016, dimana total debt to total asset ratio (DAR) perusahaan sebesar $28,4 \%$, totaldebt to equity ratio (DER) sebesar $40,7 \%$ dan long term debt to equity ratio (LDER) sebesar 5,3\%. Hal ini mengindikasikan bahwa penggunaan hutang terbesar perusahaan terjadi pada tahun 2016. Besarnya penggunaan struktur modal perusahaan pada tahun 2016 seiring dengan peningkatan penggunaan biaya rata-rata tertimbang sebesar $0,24 \%$ atau paling tinggi dibandingkan dengan tahun-tahun yang lain. Dibandingkan dengan tahun 2017 dimana WACC perusahaan sebesar 0,21\% dan tahun 2018 sebesar 0,16\%.

Nilai weighted avarage cost capital (WACC) perusahaan terendah terjadi pada tahun 2018, dimana total debt to total asset ratio (DAR) 30,6\%, total debt to equity ratio (DER) sebesar $46,9 \%$ dan long term debt to equity ratio (LDER) sebsar $6,7 \%$. Hal ini mengindikasikan bahwa penggunaan hutang terendah perusahaan terjadi pada tahun 2018. Rendahnya penggunaan struktur modal perusahaan pada tahun 2018 seiring dengan penggunaan biaya rata-rata tertimbang sebesar $0,16 \%$ atau paling rendah dibandingkan dengan tahun-tahun yang lain yaitu pada tahun 2016 sebesar $0,24 \%$ dan tahun 2017 sebesar 0,21\%.

Penggunaan komposisi jumlah hutang jangka panjang dan jumlah modal sendiri secara optimal terjadi pada tahun 2018 sehingga biaya modal rata-rata tertimbang berada pada posisi paling rendah. 


\section{KESIMPULAN DAN SARAN}

\section{Kesimpulan}

1. Perusahaan rokok yang terdaftar di Bursa Efek Indonesia selama periode 2016-2018 dalam menetapkan kebijakan struktur modalnya cenderung menggunakan modal sendiri yang lebih besar daripada modal hutang. Hal ini dapat diketahui dari proporsi modal sendiri yang lebih besar dibandingkan dengan proporsi hutang.

2. Berdasarkan hasil analisis laporan keuangan terhadap rasio rasio keuangan perusahaan, yakni total debt to total assets (DAR), total debt to equity ratio (DER) dan long time debt to equity ratio (LDER) pada perusahaan rokok yang terdaftar di Bursa Efek Indonesia, Wismilak Inti Makmur (WIIM) mempunyai struktur modal yang paling optimal dengan nilai WACC terendah yaitu pada tahun 2016 sebesar $0,12 \%$, pada tahun 2017 sebesar 0,04\% dan pada tahun 2018 sebesar 0,04.

3. Hasil analisis menyatakan bahwa struktur modal yang optimal pada perusahaan rokok yang terdaftar di Bursa Efek Indonesia periode 20162018 terjadi pada tahun 2018, yaitu pada saat biaya modal rata-rata tertimbang perusahaan minimum dengan proporsi total debt to total asset eatio (DAR) perusahaan sebesar 30,6\%, total debt to equity ratio (DER) perusahaan sebesar $46,9 \%$ dan long term debt to equity ratio (LDER) perusahaan sebesar $6,7 \%$.

\section{Saran}

1. Dalam menentukan krbijakan struktur modal, manajemen harus cermat dan lebih berhati-hati karena akan berdampak sangat luas terhadap keberlanjutan perusahaan.

2. Perusahaan diharapkan tetap memperhatikan kebijakan struktur modal karena hal tersebut dapat menjadi penentu biaya modal perusahaan yang selanjutnya akan menentukan nilai perusahaan karena naik turunnya nilai perusahaan merupakan salah satu faktor utama yang menjadi pertimbangan investor dalam berinvestasi pada perusahaan.

3. Penelitian ini sangat terbatas, oleh karena itu peneliti selanjutnya diharapkan dapat memperluas penelitian dengan cara memperpanjang periode penelitian dengan menambah tahun penelitian dan juga memperbanyak jumlah sampel pada penelitian yang akan datang.

\section{DAFTAR PUSTAKA}

Ariawan, \& Vebriyanti. (2019). Determinan Struktur Modal pada Perusahaan Sub Sektor Kosmetik yang Go Publik di Bursa Efek Indonesia. Jurnal Ekonomi Islam.

Arif. (2018). Keputusan Struktur Modal , Faktor Determinan dan Dampaknya Pada Nilai Perusahaan: Studi Komparatif Antara Perusahaan Manufaktur Syariah dan Non Syariah. 608-612.

Brigham, E. F., \& Joel, F. H. (2011) Dasar-dasar Manajemen Keuangan. Jakarta. 
Dwiani, S. (2016). Analisis Faktor-Faktor Yang Mempengaruhi Struktur Modal Pada Perusahaan Manufaktur Yang Listing Di Bursa Efek Indonesia. Jurnal Ekonomi Universitas Riau, 18(3).

Fadah, I. (2013). Manajemen Keuangan (Suatu Konsep Dasar)

Fahmi. (2014). Pengantar Manajemen Keuangan. Penerbit Alfabeta. Bandung.

Hafsah, \& Sari, S. S. (2015). Analisis Struktur Modal Terhadap Kinerja Keuangan pada Perusahaan Properti dan Real Estate yang Terdaftar di BEI. Jurnal Riset Akuntansi Dan Bisnis, 15(1), 52-64.

Harjito, A., \& Martono. (2011) Manajemen Keuangan. Penerbit Ekonisia. Yogyakarta.

Hermawan, H. (2015). .Jurnal Manajemen Dan Bisnis Indonesia Vol. 1 No. 2 Desember 2015. Jurnal Manajemen Dan Bisnis Indonesia, 1(2), 143-161.

Kamaludin, \& Indriani (2012). Manajemen Keuangan. Penerbit CV Bandar Maju. Bandung.

Margaretha. (2014). Teori dan Aplikasi Manajemen Keuangan Investasi dan Sumber Dana Jangka Panjang.

Mulyawati, A. R., \& Banani, A. (2015). Struktur Modal Pada Perusahaan SektorPariwisata, Restoran Dan Hotel Yang Terdaftar Di Bursa Efek Indonesia. 340-362.

Prasasti, N. H. (2018). Struktur Modal Perusahaan (Studi Empiris pada Perusahaan Real Estate \& Property yang Terdaftar di BEI 2011-2016).

Puspitasari, N. W. C. (2018). Analisis Pengoptimalan Struktur Modal pada Perusahaan Manufaktur di Bursa Efek Indonesia pada Tahun 2013-2017

Rahayu, R. P. (2016) Analisis EBIT-EPS Terhadap Struktur Modal Optimal pada PT Semen Indonesia (PERSERO) Tbk. Jurnal Akuntansi dan Investasi, 1 (1), 77-92

Riyanto, Bambang. (2011). Dasar-dasar Pembelanjaan Perusahaan. Yogyakarta.

Rustam, M. (2015). Penentuan Struktur Modal Optimal Pada Perusahaan Sektor Properti, Real Estate, dan Kontruksi yang Terdaftar di Bursa Efek Indonesia. Jurnal Ekonomi Bisnis Dan Kewirausahaan, 4(1), 94. https://doi.org/10.26418/jebik.v4i1.11463

Sartono, A. (2010). Manajemen Keuangan; Teori dan Aplikasi. Yogyakarta.

Siliwadi, D. N., \& Muliawani, S. H. (2018). Al-Amwal: Journal of Islamic 
Economic Law September 2018, Vol. 3, No. 2 https://ejournal.iainpalopo.ac.id/index.php/alamwal/index. 3(2), 2-17. Sjahrial, D. (2013). Analisis Laporan Keuangan. Penerbit Bumi Aksara,

Sudana. (2011). Manajemen Keuangan Perusahaan. Penerbit Erlangga. Jakarta.

Sugiyanti. (2017). MANUFAKTUR YANG TERDAFTAR DI BURSA EFEK INDONESIA.

SULISTIO, \& SAIFI. (2017). Analisis Penentuan Struktur Modal yang Optimal untuk Meningkatkan Nilai Perusahaan (Studi pada PT . Astra Graphia TbkPeriode 2013-2015 ). Jurnal Administrasi Bisnis, 48(1), 37-45.

Sutrisno. (2009). Manajemen Keuangan; Teori, Konsep dan Aplikasi. Penerbit Ekonisia. Yogyakarta.

Tampubolon. (2013). Manajemen Keuangan; Konseptual, Problem, dan Studi Kasus. Penerbit Ghalia Indonesia.

Yoshendy, A., Achsani, N. A., \& Maulana, T. N. A. (2016). Analisis FaktorFaktor yang Mempengaruhi Struktur Modal Perusahaan Barang Konsumsi di BEI tahun 2002 - 2011. Jurnal Bisnis Dan Manajemen, 16(1), 47-59. https://doi.org/10.24198/jbm.v16i1.34 